\title{
Rating the Potential Landscape Changes through the Visual Resource Inventory in North Metn Lebanon
}

\author{
AlJammal E..$^{1,2 *}$, Shahnov V. ${ }^{2}$, Samaha S. ${ }^{1}$ \\ ${ }^{1}$ Department of Landscape, Faculty of Agriculture, Lebanese University, Lebanon \\ ${ }^{2}$ Department of Landscape, Faculty of Ecology and Landscape Design, University of Forestry, Bulgaria \\ *Corresponding Author
}

Received: 03 Nov 2020; Received in revised form: 26 Jan 2021; Accepted: 14 Feb 2021; Available online: 28 Feb 2021

(C)2021 The Author(s). Published by Infogain Publication. This is an open access article under the CC BY license

(https://creativecommons.org/licenses/by/4.0/).

\begin{abstract}
North Metn is known for its miscellaneous landscapes varying from mountainous, coastal, agricultural, natural, rural, urban and industrial. However its land-cover, land-use and landscape structures are highly affected by manmade and natural means of transformation throughout a short period of time. Since the assessment of these changes is essential for any landscape management in the district, the Visual Resource Inventory (VRI) was selected for that purpose. VRI provides the basic visual resource data for future landscape planning purposes in the evaluation area. The results were analyzed for the district's visual potential based on several criteria. It is essentially used to rate the landscape for its Scenic Quality and Sensitivity Level within Distance Zones delineated. North Metn is distinguished by its valuable scenic quality and panoramic landscape views taking into account the users Landscape Importance and the particular Viewing Locations threatened by drastic changes, eighty-two Viewpoints (VP) were selected to be assessed using the VRI methods. Each VP was decomposed by its Landscape Elements in the Foreground, Middle and Background Extent taking into consideration its forms, textures, lines and colors. Each VP Scenic Quality (SQ) was rated for its Integrity, Vividness and Harmony while the View Importance (VI) was rated for its VP, Viewed Landscape and Viewer Concern. Later on, the SQ and the VI ratings will provide rankings ranging from Very high Scenic Inventory Value (SIV) rate to a Very Low SIV rate. North Metn's landscape was classified within three landscape classes depending on each rate.
\end{abstract}

Keywords - Landscape character, landscape elements, Scenic inventory value, Scenic quality rating, view importance rating and viewpoints.

\section{INTRODUCTION}

Around the world, rates of land change surge increased greatly over the next $20-50$ years, as human populations continue to grow and migrate (Alig et al. 2004; Theobald 2005) Hence, Human social and economic activities drive land change at all scales, and may enhance or hinder the movement of materials via wind, water, and biological and social vectors, sometimes in surprising ways that cut across scales (Kareiva et al, 2007; Peters et al., 2008. Urbanization, in particular, alters both biotic and abiotic ecosystem properties within surrounding, and even at great distances from urban areas (Grimm et al. 2008). Besides the Mediterranean being one of the most prominent and vulnerable climate change hotspots (Giorgi F. 2006, Kim
GU et al, 2019), other factors were eminent in the recent Mediterranean region's characterization such as: land abandonment, tourism development, population concentration along the coast, the construction of extended transportation networks (Burke \& Thornes, 1998) and the accelerated socio-economic changes (Arianoutsou M., 2001). Thus, this region is witnessing landscape changes because of the dynamic equilibrium between humans and the Mediterranean environment resulting in a remarkably rich landscape. (Arianoutsou M., 2001)

Landscape means an area, as perceived by people, whose character is the result of the action and interaction of natural and/or human factors; (European Landscape Convention, 2000) Therefore, any study related to 
landscapes is often considered subjective especially when it comes to Visual Resources which The Bureau of Land Management (BLM) in the United States (US) has defined as: the visible physical features of a landscape (e.g., land, water, vegetation, animals, structures, and other features). And since all land has inherent visual values that warrant different levels of management (BLM, 2011), they have been developing the Visual Resource Inventory (VRI). It develops, refines and implements visual analysis and management systems. It provides a tool for assessing the visual qualities of the landscape in objective terms (BLM, 2016b). The VRI is implemented by governments, environmental ministries, consultants and NGO's throughout the years for future sustainable planning purposes and it is updated thoroughly.

Lebanon's main landscape visual resources were determined by topography which has always played a decisive role in the history of its settlements and still is to date: It has granted Lebanon its magnificent landscapes (mountains, valleys, cirques, plains, etc.), enriching its potentials and its quality of life (SDATL, 2005). However, intensive urban sprawl, increasing road networks, lack of urban planning, agricultural intensification, and carelessness of natural, cultural and visual resources, political actions, wars and land abandonment are widespread landscape change processes. Its capital Beirut and its surroundings have an average urban growth rate of $1.8 \mathrm{~km} 2$ per year and it continues to increase along the coastal zone and the nearby mountain, greatly reducing the green space and the rural character of these areas. (Faour G., 2014) North Metn is one of the casas combining the coastal zones and the mountainous areas, forming a large variety of landscape to study.

North Metn is a casa near Beirut, enclosing 100 localities under 52 municipalities. It is a living example of the anthropogenic changes that a landscape could face. Therefore, in order to understand the impact of the changes, the VRI should be implemented as a basic guide in order to evaluate the status of any future planning to achieve sustainable development plans. Thus, throughout this paper, this inventory's methodology will be detailed and the results will be analyzed within specific viewpoints after classifying the North Metn's landscape.

\section{Materials and methods}

The VRI has proved to be an efficient way in quantifying the landscape in order to achieve maximum sustainability, therefore, it was developed specifically to meet requirements and designed to work for many types of landscapes and visual settings. It considers, for instance, the context of a park area's visual setting and provides a framework for understanding and protecting the scenic values within that context (National Park Services, 2016). Thus, it helps in recognizing the need to develop a comprehensive approach to assess scenic values of landscapes and their surrounding areas, to develop strategies to protect them as a resource for future generations and to evaluate the scenic resources under its jurisdiction and to develop management objectives for those resources (Meyer and Sullivan, 2016).

The inventory process is a systematic description of the landscape characters, visual elements, scenic quality, sensitivity level and importance to visitor experience and interpretive goals for important views inside and outside studied areas. (BLM, 2016b). It takes into consideration the detailed forms and descriptive views of a landscape with the visual receptors and the view amenity. Hence visual assessment of the landscape using these tools establishes identifiable, consistent qualities that can be described and measured (Meyer and Sullivan, 2016).

Therefore, after all the transformation in the landscapes of North Metn, accomplishing several goals in protecting, managing should be executed and Visual Resource Inventory is one of the newest updated methodologies to help in this matter.

The inventory consists of choosing viewpoints based on different criteria. Then, it starts with a scenic quality evaluation, sensitivity level analysis, and a delineation of distance zones. Based on these three factors, the regions of North Metn are placed into one of four visual resource inventory classes. These inventory classes represent the relative value of the visual resources. Classes I and II being the most valued, Class III representing a moderate value, and Class IV being of least value (BLM, 2011). Usually, the implementation options and the detail of the inventory will vary with the visual character of the landscapes being inventoried.

The components of landform, land cover including urban areas, infrastructure and water as per the New Zealand Landscape Classification Guide helped in recognizing that landscapes surround and are experienced from a multiple of geometrical perspectives that can be obtained from movement and exploration (Brabyn, 2006). Therefore, the landscape of North Metn was classified as coastal, urban, rural and mountainous after multiple field visits throughout 2019's summer and 2020's winter, (Fig. 1). 


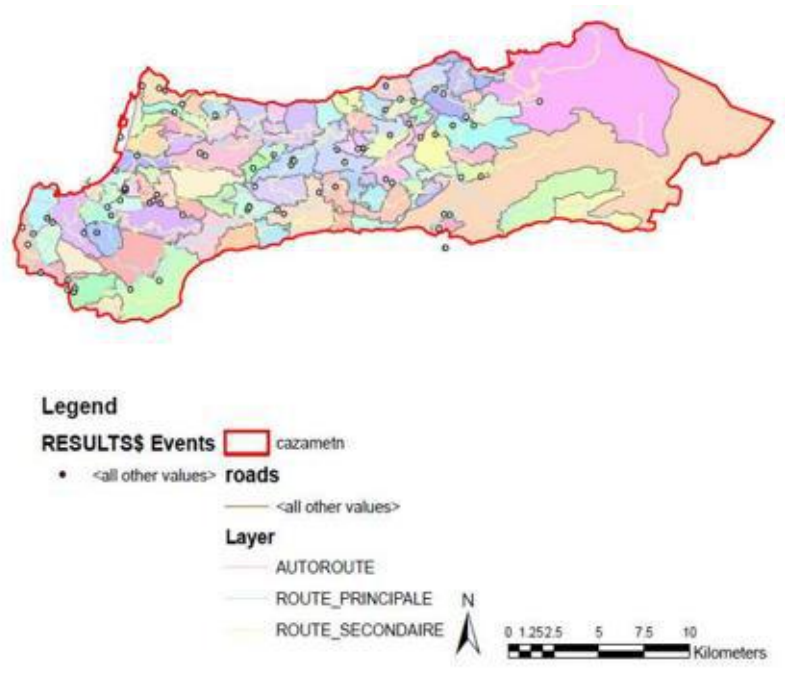

from both public and private viewpoints and views from sensitive receptors within designated landscapes.

During field visits, the altitude, distance from view, GPS coordinates of each viewpoint was registered. And each viewpoint had its unit name; for example, the region of Bikfaya's unit name was: BKFA19_1 where 19 shows the year of the photo taken and the 1 stands for the $1^{\text {st }}$ viewpoint taken for this region.

Besides, the description of the weather, observer position and view direction were also stated and taken into consideration. Later on, a Form of Landscape Description $\&$ Scenic Quality and a form of View Importance were filled as described in the Table 1 (Meyer and Sullivan, 2016).

Fig. 1: Map of viewpoints distribution in North Metn

Choosing the right viewpoints was the key to the inventory based on the points considering a human's normal field of vision and panoramic view, locations which represent a range of near-, middle- and long-distance views, views

Table 1: Scenic Inventory Value Factors

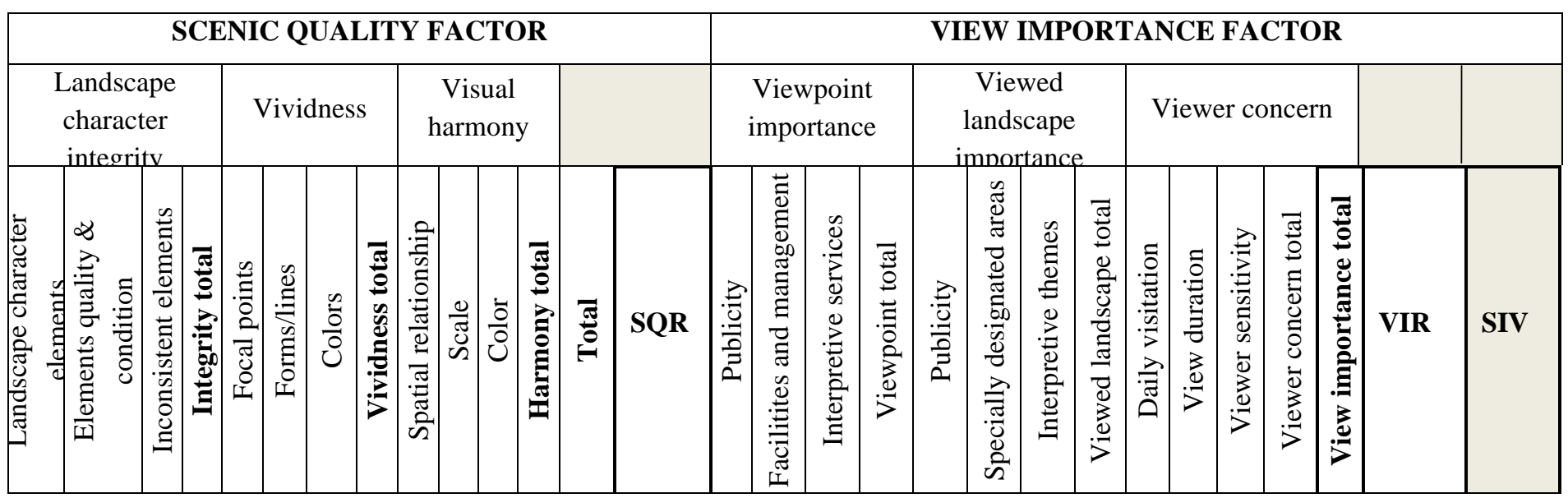

The Landscape Description and Scenic Quality form takes into consideration the View type, character type, landscape elements and Design elements based on Landscape Character Integrity, Vividness and Visual Harmony in order to obtain the Scenic Quality Rating (SQR) The SQR is defined as the value of the viewed landscape based on its perceived visual attractiveness, as determined by the aesthetic composition of the visual elements. The Rating goes from A with the highest scenic quality to $\mathrm{E}$ with the lowest (BLM, 2016c).

Whereas the View importance of the viewed landscape, viewpoints and the viewer take into consideration the Viewed landscape Importance, the Viewpoint Importance and the Viewer Concern in order to have the View
Importance Rating (VIR) going from 1 as the highest View Importance to 5 as the lowest (BLM, 2016c).

Eventually, the Scenic Quality Rating and the View Importance Rating will give the Scenic Inventory Value (SIV) for future landscape planning and environmental purposes in North Metn. 
Table 2: SIV Rating Matrix

\begin{tabular}{|l|c|c|c|c|c|}
\hline \multirow{2}{*}{ Scenic Quality } & \multicolumn{5}{|c|}{ View Importance Rating } \\
\cline { 2 - 6 } & 1 & 2 & 3 & 4 & 5 \\
\hline A & VH & VH & VH & H & M \\
\hline B & VH & VH & H & M & L \\
\hline C & H & H & M & L & L \\
\hline D & H & M & L & VL & VL \\
\hline E & M & L & VL & VL & VL \\
\hline
\end{tabular}

The Scenic Inventory Value (SIV) is the combination of SQR and VIR into a single measure. The SIV is derived using a matrix as seen in TABLE 2 to arrive at one of five SIV going from (VH) very high to (VL) very low.

\section{RESULTS AND DISCUSSIONS}

After the implementation of the VRI in North Metn after collecting all the data needed, a summarizing table was created as seen in TABLE 3 below, showing in the end column the SIV of each landscape.

The actual data was then imported into GIS as shape files in order to materialize the SIVs throughout North Metn and to help in analyzing the data within its context. The main two factors studied were the altitude and the Land use.

At the end, the topography of North Metn do play a decisive role in the creation of its landscapes and in the distribution of its land use. Both remaining key factors in comprehending the scenic quality of North Metn leading the way in understanding the human intervention's impact.

Table 3: Scenic Inventory Value results

\begin{tabular}{|c|l|c|c|c|}
\hline VP & UNIT NAME & SQR & VIR & SIV \\
\hline 1 & ABMZ19_1 & $\mathbf{C}$ & $\mathbf{3}$ & $\mathbf{M}$ \\
\hline 2 & ABMZ19_2 & $\mathbf{D}$ & $\mathbf{4}$ & $\mathbf{V L}$ \\
\hline 3 & AEQ19_1 & $\mathbf{C}$ & $\mathbf{3}$ & $\mathbf{H}$ \\
\hline 4 & AEQCH19_1 & $\mathbf{C}$ & $\mathbf{3}$ & $\mathbf{M}$ \\
\hline 5 & ANT19_1 & $\mathbf{D}$ & $\mathbf{3}$ & $\mathbf{L}$ \\
\hline 6 & AS19_1 & $\mathbf{B}$ & $\mathbf{3}$ & $\mathbf{H}$ \\
\hline 7 & ATCH19_1 & $\mathbf{B}$ & $\mathbf{4}$ & $\mathbf{M}$ \\
\hline 8 & AZBD19_1 & $\mathbf{B}$ & $\mathbf{2}$ & $\mathbf{V H}$ \\
\hline 9 & BAY-MT20_1 & $\mathbf{D}$ & $\mathbf{3}$ & $\mathbf{L}$ \\
\hline 10 & BAY-MT20_2 & $\mathbf{C}$ & $\mathbf{3}$ & $\mathbf{M}$ \\
\hline 11 & BBMNA19_1 & $\mathbf{B}$ & $\mathbf{2}$ & $\mathbf{V H}$ \\
\hline 12 & BDT19_1 & $\mathbf{B}$ & $\mathbf{3}$ & $\mathbf{H}$ \\
\hline 13 & BDT19_2 & $\mathbf{B}$ & $\mathbf{3}$ & $\mathbf{H}$ \\
\hline
\end{tabular}

\begin{tabular}{|c|c|c|c|c|}
\hline 14 & BKFA19_1 & B & 2 & VH \\
\hline 15 & BKFA19_1 & B & 3 & $\mathbf{H}$ \\
\hline 16 & BKFA19_2 & B & 3 & $\mathbf{H}$ \\
\hline 17 & BMK19_1 & $\mathbf{C}$ & 1 & H \\
\hline 18 & BMNA19_1 & B & 2 & VH \\
\hline 19 & BMNA19_2 & D & 4 & VL \\
\hline 20 & BR19_1 & D & 3 & $\mathbf{L}$ \\
\hline 21 & BSK-AEA19_1 & $\mathbf{A}$ & 2 & VH \\
\hline 22 & BSKTA19_1 & B & 4 & $\mathbf{M}$ \\
\hline 23 & BSLM19_1 & B & 2 & VH \\
\hline 24 & BTGN19_1 & $\mathbf{A}$ & 2 & VH \\
\hline 25 & BZDN19_1 & B & 2 & VH \\
\hline 26 & BZDN19_2 & $\mathbf{A}$ & 2 & VH \\
\hline 27 & BZDN19_3 & B & 2 & VH \\
\hline 28 & CHWA19_1 & $\mathbf{C}$ & 3 & $\mathbf{M}$ \\
\hline 29 & DBMRN20_1 & $\mathbf{E}$ & 2 & $\mathbf{L}$ \\
\hline 30 & DCH19_1 & B & 3 & $\mathbf{H}$ \\
\hline 31 & DH-A19_1 & D & 3 & $\mathbf{L}$ \\
\hline 32 & DHCH19_1 & $\mathbf{A}$ & 2 & VH \\
\hline 33 & DHCH19_2 & $\mathbf{A}$ & 2 & VH \\
\hline 34 & DH-Z19_1 & D & 3 & $\mathbf{L}$ \\
\hline 35 & DLB19_1 & B & 2 & VH \\
\hline 36 & DLB19_2 & B & 3 & $\mathbf{H}$ \\
\hline 37 & DM19_1 & $\mathbf{C}$ & 3 & $\mathbf{M}$ \\
\hline 38 & DO19_1 & B & 2 & VH \\
\hline 39 & ECH19_1 & D & 4 & VL \\
\hline 40 & ENM19_1 & D & 3 & $\mathbf{L}$ \\
\hline 41 & ENM19_2 & D & 4 & VL \\
\hline 42 & ENM19_3 & B & 3 & $\mathbf{H}$ \\
\hline 43 & ENM19_4 & $\mathbf{C}$ & 3 & $\mathbf{M}$ \\
\hline 44 & FNR19_1 & D & 3 & $\mathbf{L}$ \\
\hline 45 & HMLY19_1 & B & 3 & $\mathbf{H}$ \\
\hline 46 & HT19_1 & D & 3 & $\mathbf{L}$ \\
\hline 47 & JAR19_1 & $\mathbf{B}$ & 2 & VH \\
\hline 48 & K_TR19_1 & $\mathbf{C}$ & 4 & $\mathbf{L}$ \\
\hline 49 & KFAQ19_1 & B & 2 & VH \\
\hline 50 & KHNCH19_1 & $\mathbf{C}$ & 2 & $\mathbf{H}$ \\
\hline 51 & MC-B19_1 & B & 2 & VH \\
\hline 52 & MC-D19_2 & $\mathbf{C}$ & 3 & $\mathbf{M}$ \\
\hline
\end{tabular}




\begin{tabular}{|c|l|c|c|c|}
53 & MCHKH19_1 & $\mathbf{C}$ & $\mathbf{3}$ & $\mathbf{M}$ \\
\hline 54 & MCHKH19_2 & $\mathbf{B}$ & $\mathbf{2}$ & $\mathbf{\text { H}}$ \\
\hline 55 & MCHR19_1 & $\mathbf{B}$ & $\mathbf{3}$ & $\mathbf{H}$ \\
\hline 56 & M-DB19_1 & $\mathbf{C}$ & $\mathbf{3}$ & $\mathbf{M}$ \\
\hline 57 & MK19_1 & $\mathbf{D}$ & $\mathbf{4}$ & $\mathbf{V L}$ \\
\hline 58 & MKMNSR19_1 & $\mathbf{C}$ & $\mathbf{3}$ & $\mathbf{M}$ \\
\hline 59 & MNSR19_1 & $\mathbf{C}$ & $\mathbf{4}$ & $\mathbf{L}$ \\
\hline 60 & MNSR19_2 & $\mathbf{C}$ & $\mathbf{3}$ & $\mathbf{M}$ \\
\hline 61 & MRJ19_1 & $\mathbf{B}$ & $\mathbf{4}$ & $\mathbf{M}$ \\
\hline 62 & MRJ19_2 & $\mathbf{C}$ & $\mathbf{3}$ & $\mathbf{M}$ \\
\hline 63 & MS-ELH19_1 & $\mathbf{B}$ & $\mathbf{3}$ & $\mathbf{H}$ \\
\hline 64 & MS-ELH19_2 & $\mathbf{C}$ & $\mathbf{4}$ & $\mathbf{L}$ \\
\hline 65 & MZK19_1 & $\mathbf{D}$ & $\mathbf{4}$ & VL \\
\hline 66 & NEM19_1 & $\mathbf{E}$ & $\mathbf{4}$ & VL \\
\hline 67 & NENM19_1 & $\mathbf{C}$ & $\mathbf{3}$ & $\mathbf{M}$ \\
\hline 68 & NNM19_1 & $\mathbf{C}$ & $\mathbf{4}$ & $\mathbf{L}$ \\
\hline 69 & NNM19_2 & $\mathbf{C}$ & $\mathbf{3}$ & $\mathbf{M}$ \\
\hline 70 & R19_1 & $\mathbf{B}$ & $\mathbf{2}$ & $\mathbf{V H}$ \\
\hline 71 & ROU19_1 & $\mathbf{E}$ & $\mathbf{5}$ & VL \\
\hline 72 & SEF19_1 & $\mathbf{D}$ & $\mathbf{3}$ & $\mathbf{L}$ \\
\hline 73 & SEF20_2 & $\mathbf{D}$ & $\mathbf{3}$ & $\mathbf{L}$ \\
\hline 74 & SEF-BH19_1 & $\mathbf{E}$ & $\mathbf{5}$ & $\mathbf{V L}$ \\
\hline 75 & TR-JDSF19_1 & $\mathbf{C}$ & $\mathbf{4}$ & $\mathbf{L}$ \\
\hline 76 & ZATR19_1 & $\mathbf{E}$ & $\mathbf{5}$ & $\mathbf{V L}$ \\
\hline 77 & ZBGH19_1 & $\mathbf{B}$ & $\mathbf{2}$ & $\mathbf{V H}$ \\
\hline 78 & ZGHN19_1 & $\mathbf{B}$ & $\mathbf{3}$ & $\mathbf{H}$ \\
\hline 79 & ZKH19_1 & $\mathbf{B}$ & $\mathbf{3}$ & $\mathbf{H}$ \\
\hline 80 & ZKH19_2 & $\mathbf{C}$ & $\mathbf{4}$ & $\mathbf{L}$ \\
\hline 81 & ZKH19_3 & $\mathbf{C}$ & $\mathbf{3}$ & $\mathbf{M}$ \\
\hline 82 & ZKT19_1 & $\mathbf{L}$ \\
\hline & & & \\
\hline
\end{tabular}

The maps below in Fig. $2 \& 3$ show the viewpoints in relation with the altitude and the land use respectively.

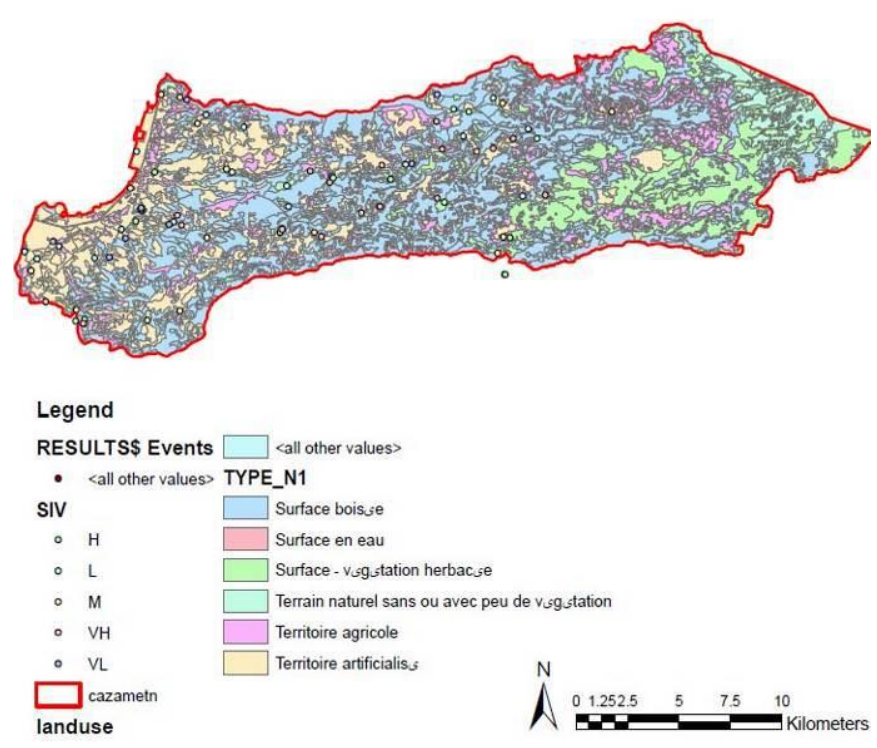

Fig. 2: Map of Viewpoints within North Metn Land use

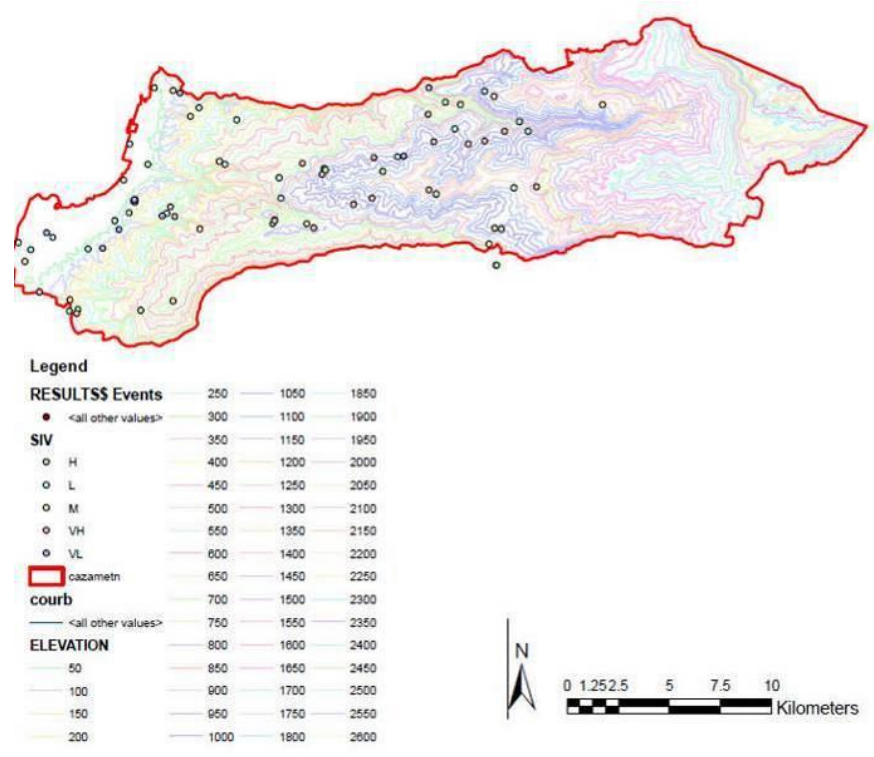

Fig. 3: Map of Viewpoints within North Metn altitudes

After analyzing the data, it's identifiable that the dominating landscape on altitudes from the sea level to $600 \mathrm{~m}$ are wooded areas and artificial anthropogenic areas. On the other hand, all wooded area, vegetation area, agricultural area and water areas were dominating for area within the 600 and 1000 meters limitation whereas, all of the landscapes above $1000 \mathrm{~m}$ were selected water areas, vegetation areas, natural areas with few vegetation and agricultural areas. Thus, the importance of sectioning the scenic quality analysis within these ranges of altitude and land use in order to classify the landscape for future protection, restoration and sustainable management proposals. Thus, now the SIV results obtained will be distributed into 3 sections based on the altitude as 
mentioned before. And based on each SIV results, the landscape will be classified based on the Manual of BLM created for VRI. Classes range from Class I to Class IV as mentioned before.

As for the SIV results of the regions between 15 to 600 meters, (fig. $4 \& 5$ ), it is clear that the SIV is always between very low and medium with a combination of $64 \%$. This result puts it in the class IV objective for providing for management activities which require major modifications if the existing character of the landscape. The level of change to the characteristic landscape can be high. Looking further into landscapes within these altitudes, the urban residential landscape characters and cement blocks are dominant (photo $1 \& 2$ ).

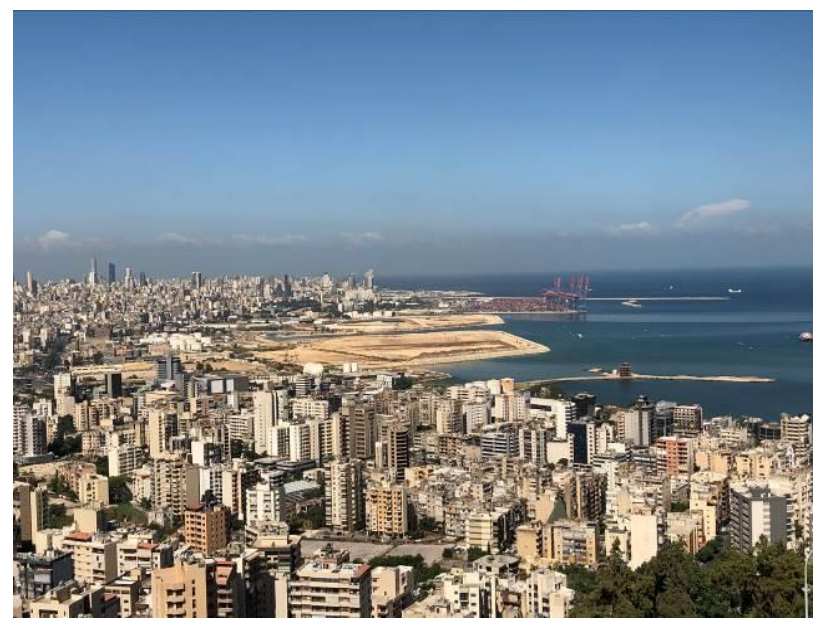

Photo 1: East North Metn Coastal landscape

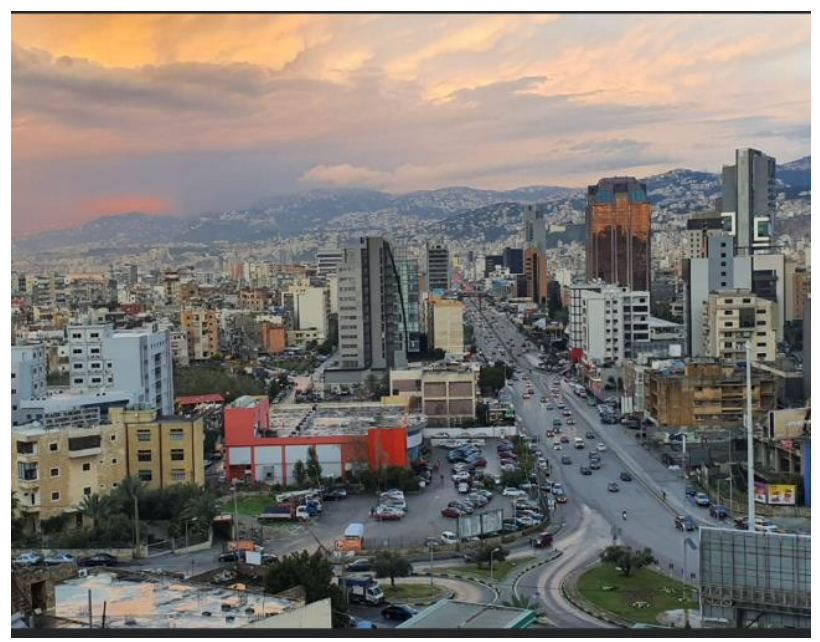

Photo 2: North Metn urban landscape

These changes that this landscape has witness dominated the view and is now the major focus of the viewer attention. Therefore every attempt of future proposals ISSN: 2456-1878 should minimize the impact of these activities through careful location, minimal disturbance and repeating the basic elements (BLM, 2011).

As for the SIV results for the regions between 620 to 1000 meters are clearly recognized for a $71 \%$ of medium to very high SIV while $29 \%$ of the rest are between very low to low (fig. $6 \& 7$ ). This shows the importance of the scenic views for the receptors where noticeably the variety of the existing landscapes and the low impact of the changes occurring (photos $3 \& 4$ ). This puts it under the class III objective to retain the existing character of the landscape. The level of change of the characteristic landscape should be moderate while management activities may attract attention but should not dominate the view of the casual observer. Thus, the basic elements found in the natural feature of the characteristic landscape

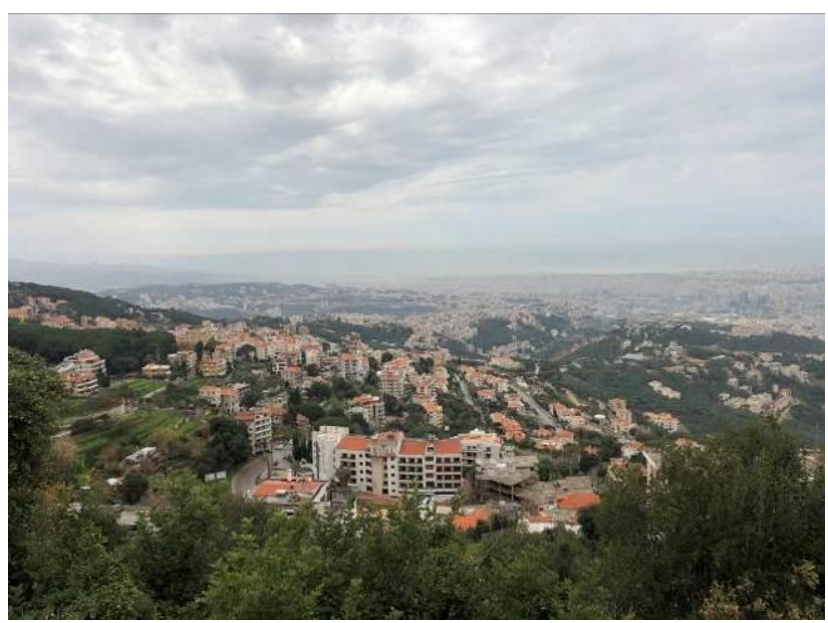

Photo 3: Rural landscapes of North Metn

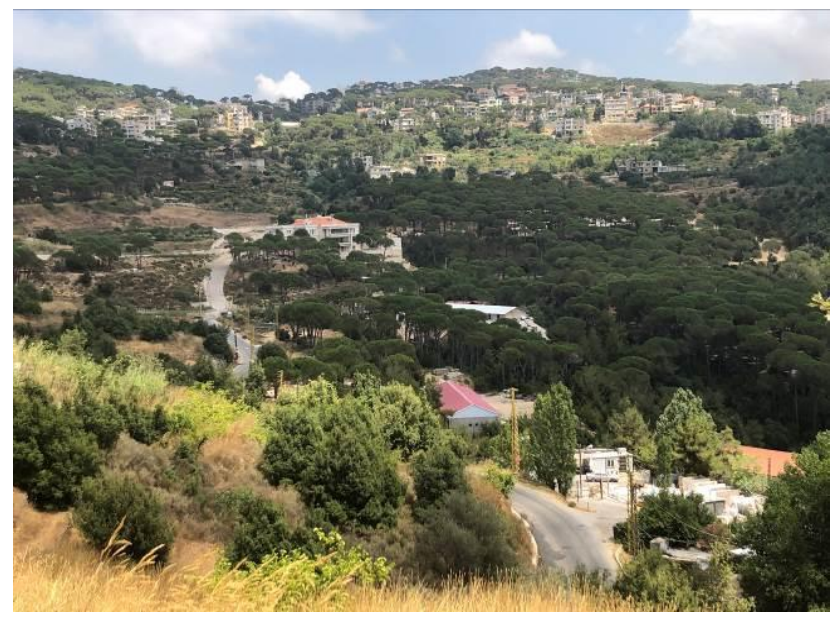

Photo 4: Rural and mountainous landscapes of North Metn

should be used in future interventions (BLM, 2011). 
At the end, the SIV results of the regions going from a thousand meters and above has a percentage of $87 \%$ from medium to very high SIVs while only $13 \%$ rates as low (fig. $8 \& 9$ ). These landscapes are unique and shows the true cultural identity of the Lebanese mountains (Photos 5 \& 6).

This landscape classifies as class II objective of retaining the existing character of the landscape whereas the level of change to the characteristic should be low. The human future activities could be seen but should not attract the attention of the casual observer. Any changes must repeat the basic elements of form, line, color and texture found in the predominant natural features of the characteristic landscape (BLM, 2011).

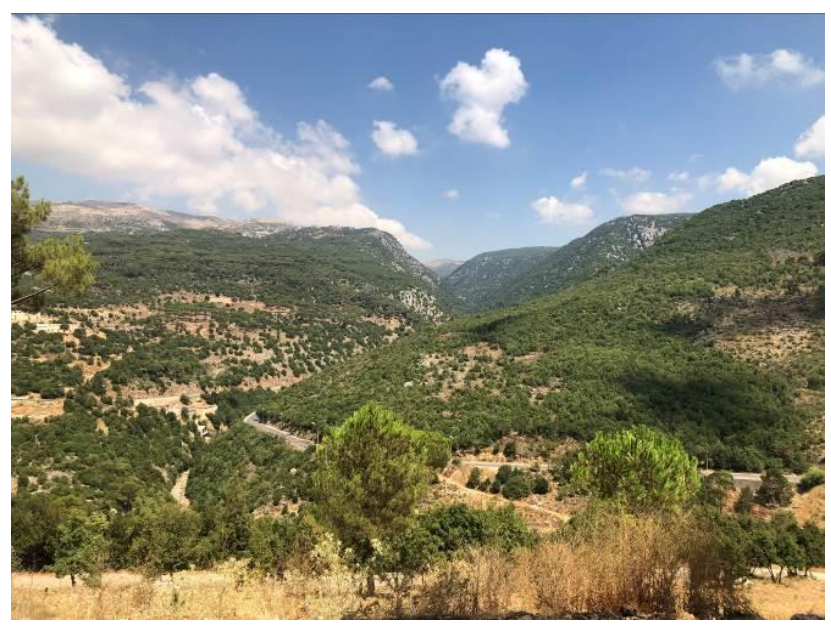

Photo 5: Mountainous landscapes of North Metn

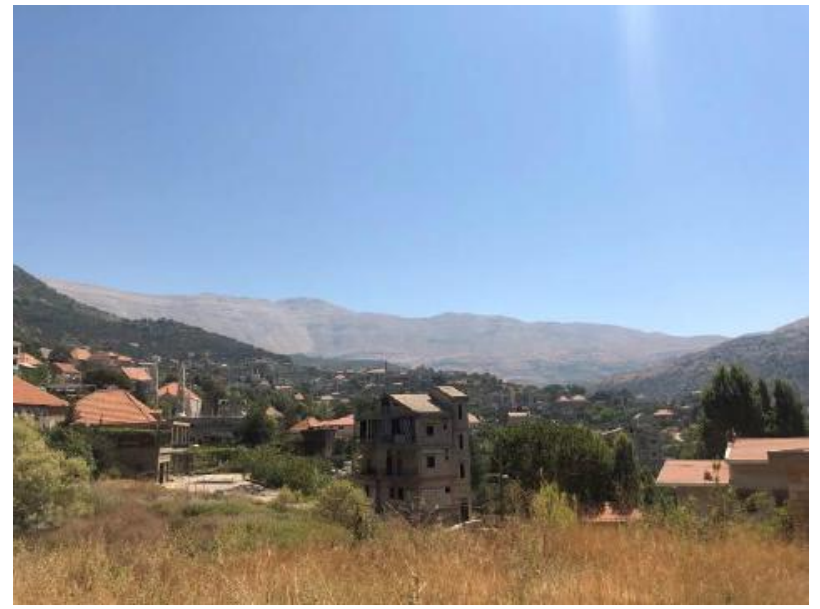

Photo 6: Highest mountain's peak in Lebanon, Sannine

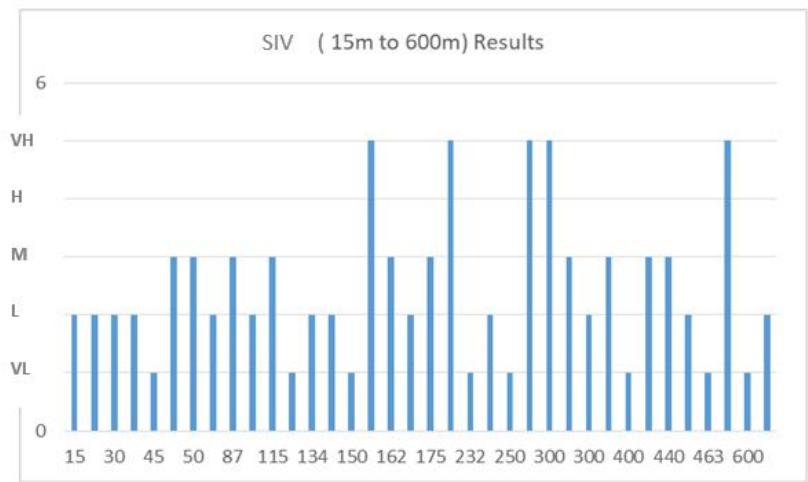

Fig. 4: SIV results of altitudes between $15 \mathrm{~m}$ to $600 \mathrm{~m}$

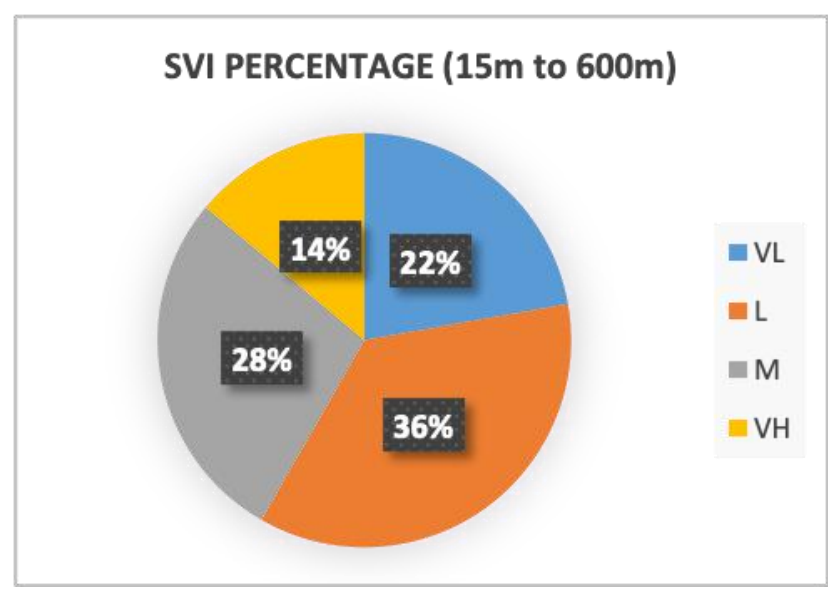

Fig. 5: SIV percentage of altitudes between $15 \mathrm{~m}$ to $600 \mathrm{~m}$

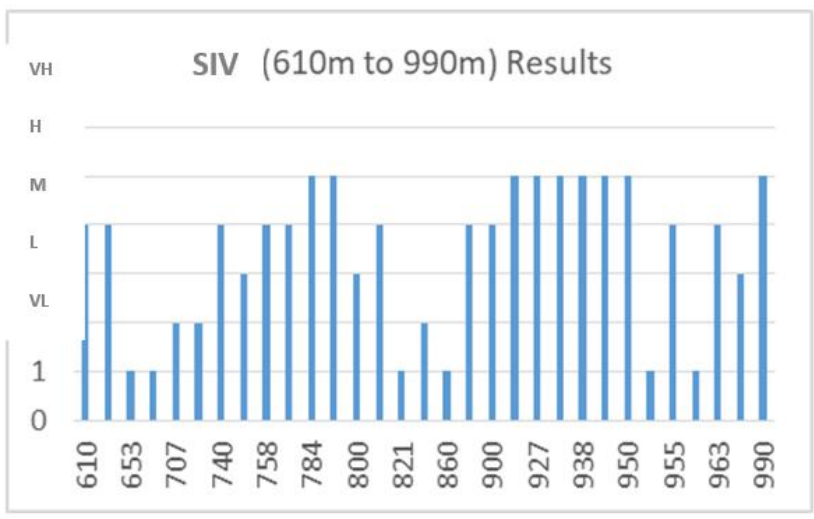

Fig. 6: SIV results of altitudes between 610m to 990m 


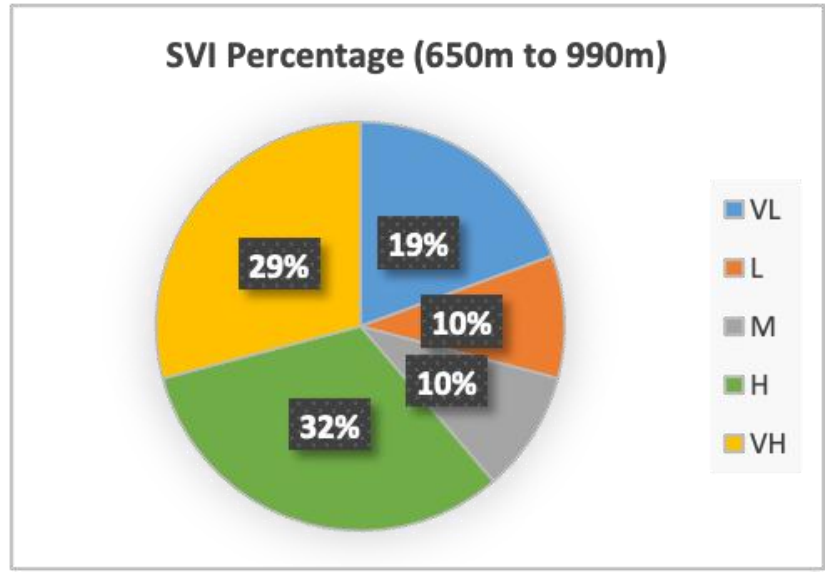

Fig. 7: SIV percentage of altitudes between $610 \mathrm{~m}$ to $990 \mathrm{~m}$

\section{SIV (1000m to $1320 m)$ Results}

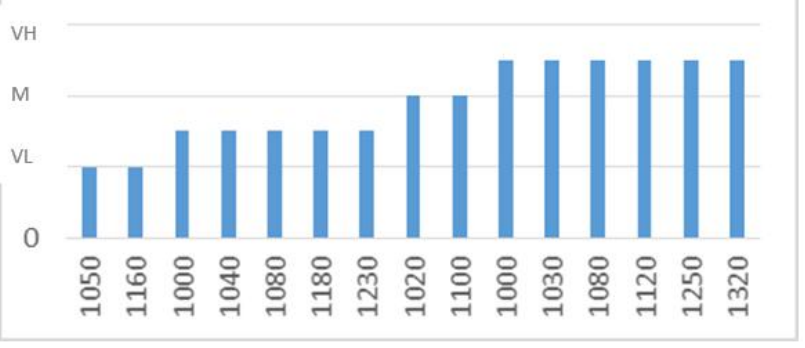

Fig. 8: SIV results of altitudes over $1000 m$

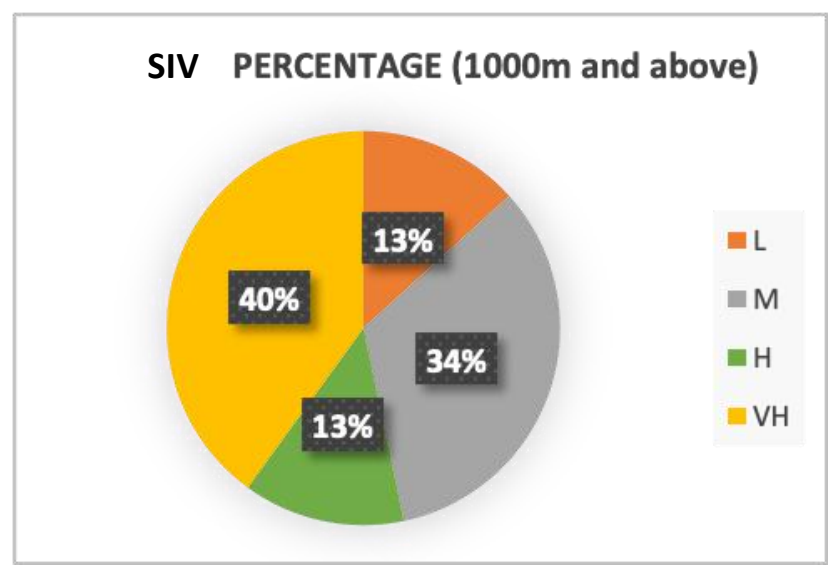

Fig. 5: SIV percentage of altitudes over $1000 \mathrm{~m}$

The descriptive information gathered in the VRI process and the scenic quality and view importance results can be used in the development of plans for the management of scenic resources.

\section{CONCLUSION}

North Metn is facing a lot of changes and concerns arising from everyday chaotic constructions on the coastal landscapes as much as on the mountainous landscapes. Even though, some changes have irreversible impacts, finding the solutions to preserve the existing cultural and patrimonial landscape and to restore the scenic quality landscapes should be the focus. By studying all the landscape characters and scenic values of North Metn, the process of preservation and restoration should be at ease in every future proposal and intervention.

Added to that, historic and cultural resources are essential to the scenic experience of the visitors and the users and the VRI incorporates historic, cultural, and other values in a measure of view importance, in addition to scenic quality.

Thus, Visual Resource Inventory is the solution to achieve objectives of reserving the cultural and historical landscapes, restoring damaged and transforming landscapes as managing and planning to new potential sustainable strategic land use. Hopefully, it would be used in all the remaining casa in Lebanon to achieve sustainable development and landscape protection and management all over the country.

\section{REFERENCES}

[1] Alig RJ, Kline JD, and Lichtenstein M. (2004). Urbanization on the US landscape: looking ahead in the 21st century. Landscape Urban Plan 69: 219-340

[2] Arianoutsou M, (2001). Landscape changes in Mediterranean ecosystems of Greece: implications of fire and biodiversity issues. Journal of Mediterranean: Ecology2: 165- 178

[3] BLM, Bureau of Land Management, (2011), Affected Environment, Environmental Consequences, And Mitigation, Section 3, pp. 3.9-1-2.

[4] BLM, Bureau of Land Management, (2016a), National Park Service Visual Resource Inventory, retrieved from https://blmwyomingvisual.anl.gov/vr-inventory/nps/

[5] BLM, Bureau of Land Management, (2016b), BLM's Visual Resource Inventory retrieved from https://blmwyomingvisual.anl.gov/vr-inventory/blm/

[6] BLM, Bureau of Land Management, (2016c), Visual Resource Inventory Methodologies retrieved from https://blmwyomingvisual.anl.gov/vr-inventory/

[7] Brabyn L, (2006), New Zealand Landscape Classification, Version II, A Classification of Visual Landscape Character, pp. 3-23.

[8] Burke, S. \&Thornes, 3. (1998). Actions taken binational governmental and non-governmental organizations to mitigate desertification in the Mediterranean. European Commission, EUR 18490 EN. Luxembourg.

[9] Council for Development and Reconstruction, SDATL (2005), National Physical Master Plan of the Lebanese Territory, pp. 5-7.

[10] European Landscape Convention, (2000), Coucil of Europe, European Treaty series- N. 176, pp. 2. 
[11] Faour G, Mhawej M, (2014), Mapping Urban Transitions in the Greater Beirut Area Using Different Space Platforms, Land 2014, 3, 941-956; doi:10.3390/land3030941, pp. 941-955.

[12] Giorgi F. (2006) Climate change hot-spots. Geophys. Res. Lett. 33, pp. 1-4.

[13] Grimm NB, Arrowsmith JR, Eisinger C, et al. (2004). Effects of urbanization on nutrient biogeochemistry of aridland streams. In: DeFries R, Asner GP, and Houghton $\mathrm{R}$ (Eds). Ecosystem interactions with land-use change. Washington, DC: American Geophysical Union.

[14] Kareiva P, Watts S, McDonald R, and Boucher T. (2007). Domesticated nature: shaping landscapes and ecosystems for human welfare. Science 316: 1866-69.

[15] Kim, GU., Seo, KH. \& Chen, D. (2019). Climate change over the Mediterranean and current destruction of marine ecosystem. Sci Rep 9,18813. Retrieved from https://doi.org/10.1038/s41598-019-55303-7.

[16] Peters DPC, Groffman PM, Nadelhoffer KJ, et al. (2008(. Living in an increasingly connected world: a framework for continental scale environmental science. Front Ecol Environ 6: 229-237.

[17] Sullivan R, Meyer M., (2016), Documenting America's Scenic Treasures: The National Park Service Visual Resource Inventory.

[18] Theobald DM. (2005). Landscape patterns of exurban growth in the USA from 1980 to 2020. Ecol Soc 10: 32. 